\title{
Early Carbamazepine Treatment May Lead to Successful Cure of Typewriter Tinnitus: A Case Report
}

\author{
Eui-Cheol Nam ${ }^{1,2}$, Woo Hyun Lee ${ }^{2}$ \\ 'Department of Otolaryngology, College of Medicine, Kangwon National University, Chuncheon, Korea \\ ${ }^{2}$ Department of Otolaryngology, Kangwon National University Hospital, Chuncheon, Korea
}

\author{
Carbamazepine의 조기 투여로 완치된 타자기 이명 1 예 \\ 남 의 철,2.이 우 현
}

강원대학교 의과대학 이비인후과학교실 ${ }^{1}$, 강원대학교병원 이비인후과 ${ }^{2}$

\begin{abstract}
Typewriter tinnitus, whose cause is thought to be neurovascular compression of the cochlear nerve, is characterized by unilateral staccato tinnitus and known to be highly responsive to carbamazepine; however, complete remission has rarely been reported. A 67-yearold male visited the clinic with a complaint of tinnitus in his right ear lasting for 2 weeks; he reported it as sounding like "roasting beans." We diagnosed him with typewriter tinnitus and started carbamazepine administration on the same day. Pure tone audiometry, auditory brainstem response (ABR) test, and magnetic resonance imaging (MRI) were performed as well. The audiogram showed symmetric hearing loss at the high-frequency region. In the ABR test, the amplitudes of waves I-V of the right ear were decreased compared to the left ear. The MRI showed the anterior-inferior cerebellar artery loop abutting the auditory nerve, which is close to the entry of the internal auditory canal. The patient's tinnitus completely disappeared after 3 weeks of carbamazepine administration. We propose that initiation of carbamazepine administration shortly after symptom onset may effectively treat typewriter tinnitus. Further study is needed to consolidate the effect of early initiation of carbamazepine administration.
\end{abstract}

Key Words: Tinnitus, Carbamazepine, Nerve compression.

Received: April 26, 2018 / Revised: June 4, 2018 / Accepted: July 2, 2018

Correspondence: Woo Hyun Lee, Department of Otolaryngology, Kangwon National University Hospital, 156 Baengnyeong-ro, Chuncheon 24289, Korea Tel: +82-33-258-9109 / Fax: +82-33-258-9486 / E-mail: sniper212@hanmail.net

\section{INTRODUCTION}

이명은 외부의 소리 자극이 없는 상태에서 머리나 귀에서 들 리는 소리로 정의하며 흔하게 관찰되는 이과적 증상이다 $(\mathrm{Ba}-$ guley et al., 2013). 이 증상이 있는 대부분의 사람들은 이러한 소리를 특별하게 생각하지 않아 병원을 찾거나 약물의 도움을 받지는 않는다. 하지만 일부의 이명 환자들은 이명 증상으로 인 해 삶의 질에 중대한 영향을 미치는 우울증, 불안, 욕구장애, 불 면과 같은 질환이 발생되기도 한다(Nondahl et al., 2007). 이러 한 이명의 발생 원인은 매우 다양하며 병인에 따른 적절한 치료 가 증상 회복의 중요한 요인이 된다.

타자기 이명(typewriter tinnitus)은 제8번 뇌신경인 와우신 경(cochlear nerve)이 전하소뇌동맥(anterior-inferior cerebellar artery, AICA)에 의해 눌림으로 발생하는 신경혈관 질환으로 전형적인 스타카토(staccato) 양상의 이명(혹은 타자기 치는 소 리, 팝콘 터지는 소리, 기관총 쏘는 듯한 소리)을 특징으로 한 다(Levine, 2006). 동일한 기전에 의해 발생하는 삼차신경통 (trigeminal neuralgia)의 치료에 carbamazepine 투여가 효과 적임에 착안해 타자기 이명의 치료에 이 약물이 사용되었고 증 상 호전에 우수한 효과를 보인다고 알려져 있다(Mardini, 1987). 하지만 carbamazepine은 심각한 간 기능 손상이나 골수 억제 등 치명적인 부작용의 가능성이 있어 약물의 사용 동안 지속적 인 혈액검사, 간기능검사 등의 모니터링이 필요하고 이로 인해 장기간 사용에 부담이 따른다(American Psychiatric Associa- 
tion, 1994).

또한 이 질환은 전형적인 이명 양상이나 약물에 대한 우수한 반응에도 불구하고 보고된 예가 드물어 진단이 이루어지기까지 많은 시간이 소요되고, 이에 따라 환자들의 증상 발생 후 적절 한 약물의 초기 투여까지 오랜 시간이 소요되는 것이 현실이다. 이 연구의 목적은 타자기 이명 환자에서 조기에 carbamazepine 을 투여하였을 때 얻을 수 있는 치료적 효과에 관하여 알아보는 것이다.

최근 저자들은 이명 발생 15 일 후에 본원을 방문한 환자를 특징적인 이명 양상 및 이학적 검사에 의거하여 타자기 이명으 로 진단하였고, 이에 3주간 carbamazepine을 투여하여 완전하 게 증상이 소멸된 증례를 경험하였기에 문헌 고찰과 함께 보고 하는 바이다.

\section{CASE REPORT}

67세의 남자 환자가 15 일 전부터 반복되는 우측 이명을 주소 로 본원 이비인후과 외래를 내원하였다. 환자가 표현하는 이명 의 양상은 콩 볶는 듯한 소리로 맥박보다 빠른 속도로 들렸으 며 한번 이명이 발생하면 5 20분가량 지속되고 하루에 수차례 씩 반복되었다. 하지만 이 환자의 이명을 유발하는 특별한 요인 은 없었다. 환자는 이명으로 인해 수면을 취하기 어려울 정도의 불편을 호소하였고 우측 이충만감이 동반되어 있으나 청력의 저하, 어지러움, 두통 등을 호소하지는 않았다.

과거력상 고혈압 이외에 특이한 병력은 없었으며 이학적 검
사상 외이도와 고막 모두 정상 소견으로 관찰되었다. 순음청력 검사에서 3 분법상 우측 $28 \mathrm{~dB} \mathrm{HL}$, 좌측 $33 \mathrm{~dB} \mathrm{HL}$ 의 청력역치 를 보였으며 양측 모두 고음으로 갈수록 청력이 저하되는 하강 형 감각신경성 난청의 양상을 나타내었고(Figure 1), 어음청취역 치 검사에서는 우측 $35 \mathrm{~dB} \mathrm{HL}$, 좌측 $38 \mathrm{~dB} \mathrm{HL}$ 로 순음청력검 사와 큰 차이가 없는 역치로 측정되었다. 청성뇌간반응검사(auditory brainstem response)에서 $90 \mathrm{~dB} \mathrm{nHL} \mathrm{I} \mathrm{V}$ 파의 파간 잠복 기는 각각 $4.2 \mathrm{~m} / \mathrm{sec}$ (우측), $4.46 \mathrm{~m} / \mathrm{sec}$ (좌측)이고 $\mathrm{V}$ 파의 잠복기 는 각각 $6.15 \mathrm{~m} / \mathrm{sec}$ (우측), $6.28 \mathrm{~m} / \mathrm{sec}$ (좌측)로 간격의 연장은 관찰되지 않았으나 이명이 있는 우측의 진폭이 I파, III파, V파 에서 각각 $0.03 \mu \mathrm{V}, 0.23 \mu \mathrm{V}, 0.11 \mu \mathrm{V}$ 로 좌측의 $0.11 \mu \mathrm{V}, 0.51 \mu \mathrm{V}$, $0.13 \mu \mathrm{V}$ 에 비해 전 영역에 걸쳐 현저하게 감소된 양상을 보였다 (Figure 2). 이명검사에서 환자의 이명은 순음, 협대역 및 백색 잡음 등 모두에서 비견할 만한 유사한 성상의 소리를 찾을 수 없었다.

환자의 문진 및 검사 결과들을 종합하여 타자기 이명을 고려 하였고 질환의 진단적 치료를 위하여 carbamazepine $200 \mathrm{mg}$ 을 1 일 저녁에 1 회 복용하도록 1 주간 처방하는 동시에 자기공명 영상(magnetic resonance imaging, MRI)을 시행하였다. 촬영한 후두와 자기공명영상(posterior fossa MRI) 소견상 우측 AICA 가 8번 신경에 근접하여(Figure 3A) 있으나 내이도(internal auditory canal)로의 혈관고리(vascular loop)의 침범은 없는 양상 이 관찰되었다(Figure $3 \mathrm{~B}$ ). 일주일 후 재방문한 환자는 carbamazepine을 투약한 다음 날 즉시 이명이 소실되어 약물치료에 효과적인 반응을 보였고 이에 2주간 동일한 용량의 약물을 추
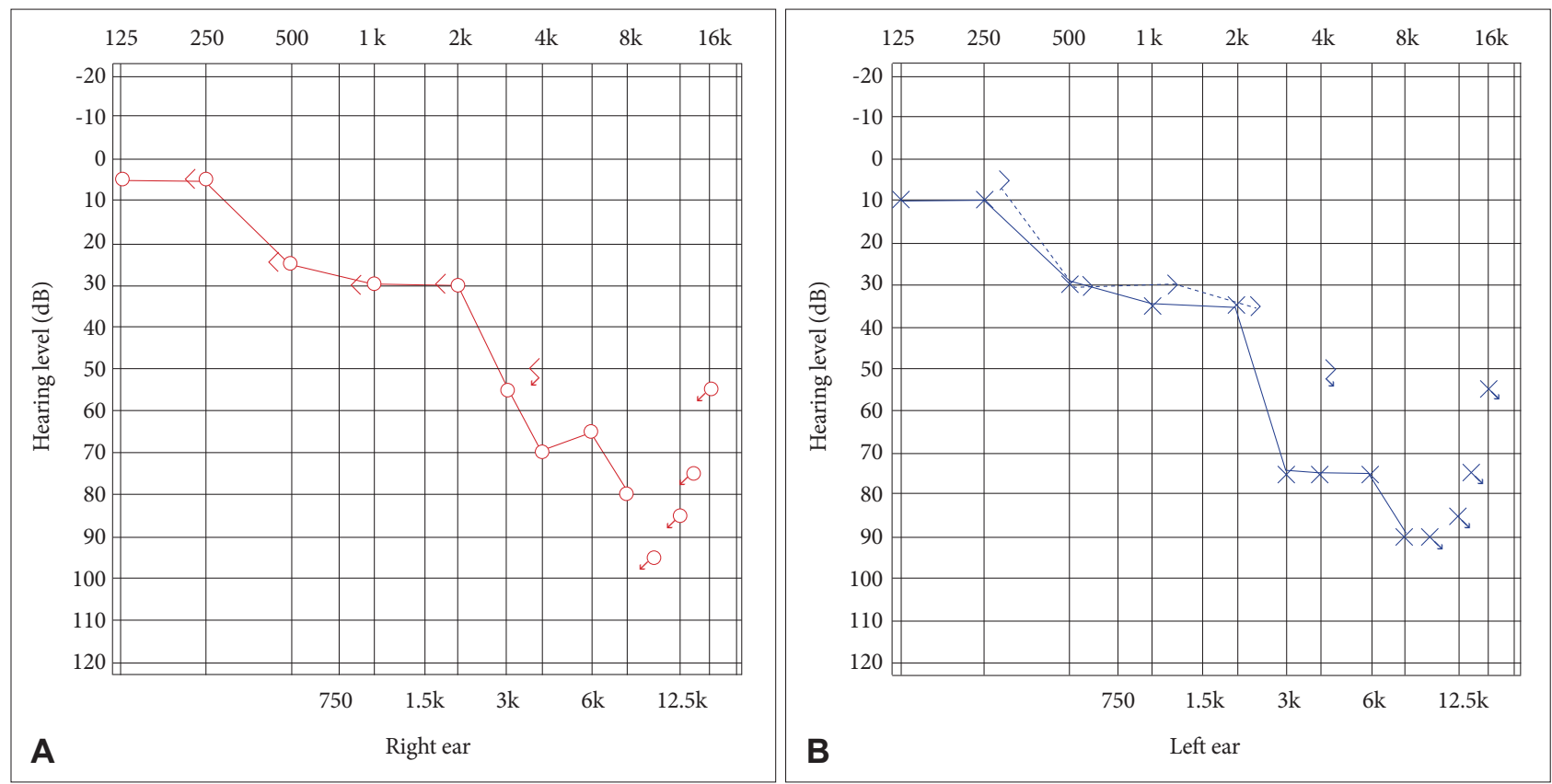

Figure 1. The audiogram shows symmetric hearing loss at the high frequency region $(A, B)$ of the patient with typewriter tinnitus in the right ear. 

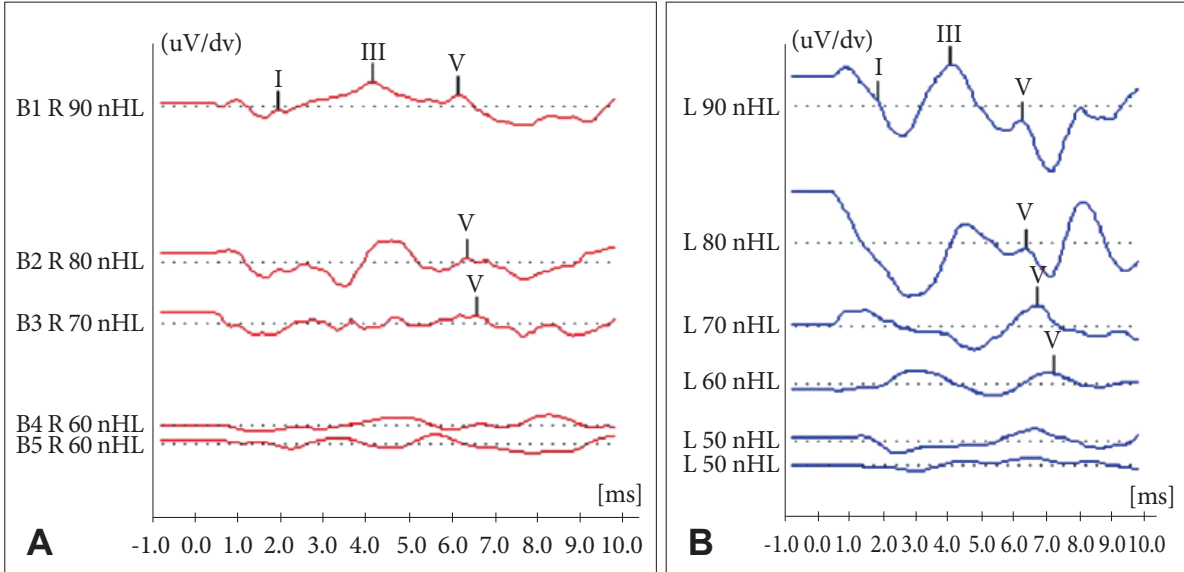

Figure 2. The auditory brainstem response test shows no latency prolongation between waves I and V. However, wave I through wave $V$ amplitude of the right ear $(A)$ decreased compared to the left ear (B).
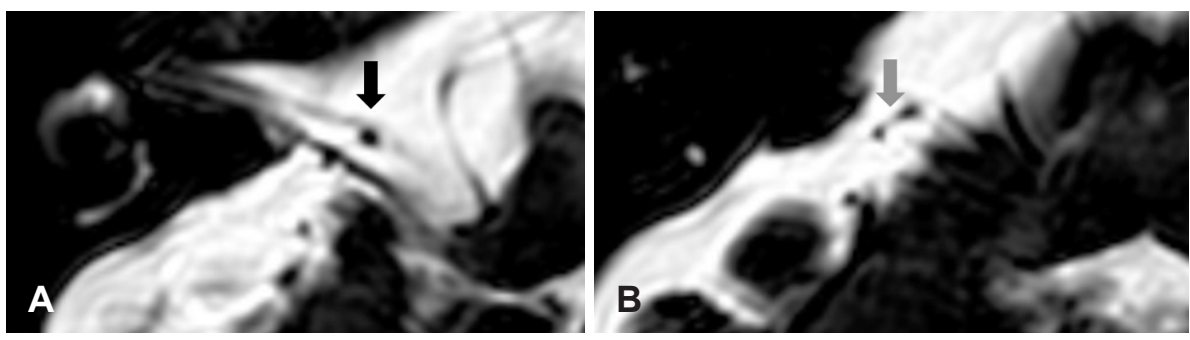

Figure 3. The AICA loop (black arrow) abuts onto the auditory nerve close to the entry of IAC (A). The AICA loop (gray arrow) does not enter the IAC (B). AICA: anterior-inferior cerebellar artery, IAC: internal auditory canal.

가 투여한 후 약물 투여를 중단하였으며 1년 6개월이 지난 현 재까지 증상이 소실된 상태에서 경과 관찰 중이다.

\section{DISCUSSIONS}

동맥에 의한 뇌신경의 압박은 신경 자체에 자극을 일으켜 과 활성 시키고, 진행할 경우 신경의 기능 저하를 유발하기도 한다. 그 예로 5 번 뇌신경의 혈관 압박에 의해 발생하는 삼차신경통 (trigeminal neuralgia), 7번 뇌신경의 압박 증상으로 유발되는 편측안면연축(hemifacial spasms), 9번 뇌신경과 연관된 설인신 경통(glossopharyngeal neuralgia) 등이 있다.

Mardini(1987)는 자신에게 발생한 ear-clicking 양상의 이명을 최초에 근육수축 이상으로 발생하는 구개근 경련(palatal myoclonus)으로 생각하고 이 질환의 치료를 위하여 고막장근(tensor tympani muscle)과 등골근(stapedial tendon) 제거 수술을 시 행받은 후에도 증상이 지속되자 이 증상이 신경학적 이상에 의 해 유발되는 것이 아닐까 하는 가정을 하였다. 이 가정을 근거로 신경감각 이상에 의해 발생하는 삼차신경통의 치료에 carbamazepine이 효과적임을 고려하여 이 약물을 투여하였고, 약물 복용 후 이명은 극적으로 호전되었으나 약의 간 독성(liver toxicity)으로 인해 투여를 중단한 후 증상이 재발하였음을 보고하 였다(Mardini, 1987).

“타자기 이명”이라는 진단은 Levine(2006)이 8번 뇌신경의 동맥 압박에 의해 유발되어 간헐적으로 발생하는 스타카토 양
상의 타자기 치는 소리, 팝콘 터지는 소리, 혹은 기관총 쏘는 듯 한 소리 등의 특징적인 이명이 동반된 6명의 환자에게 carbamazepine을 투약한 후 우수한 치료 결과를 보인 증례를 보고하 며 처음으로 명명하였다(Levine, 2006). 이후의 연구자들에 의 해 타자기 이명의 치료에 carbamazepine의 치료가 효과적이라 는 증례 보고들이 있었으며(Bae et al., 2017; Brantberg, 2010; Mathiesen \& Brantberg, 2015; Nam et al., 2010), 최근에는 이 질환의 진단을 위한 중요한 기준으로 진단적인 carbamazepine 투여로 그 효과를 관찰하는 것이라는 연구 결과가 있었다(Sunwoo et al., 2017).

국내에 발표된 타자기 이명에 대한 증례는 드물어 8번 뇌신 경 혈관 압박(neurovascular compression)에 대한 7예의 보고 가 있으며 이 중 5 명은 이명과 동시에 현훈을 호소하였으며 본 증례와 같이 단독적인 이명 증상은 2예에 불과하였다(Kim et al., 2014). 이와 같이 전형적인 임상 양상과 carbamazepine에 관한 우수한 반응에도 불구하고 질환의 희소성으로 인해 타자 기 이명이 발병된 환자들은 적절한 진단을 받지 못해 약물이 투여되기까지 대부분 오랜 시간 동안 여러 병-의원을 전전하게 된다. 이와 같이 진단 및 치료에 시간이 지체되면 압박에 의한 8 번 뇌신경의 변화는 더욱 진행하여 질환의 예후에 영향을 줄 것으로 추측된다. 실제로 이 질환에 이환된 환자의 청성뇌간반 응검사의 변화는 이환 기간이 증가할수록 진행하여 초기 단순 한 신호전달장애인 II파 감소에서 4년 정도 경과 후 신경의 국소 탈수초화를 나타내는 I III파 간 간격 연장이 보이고 마침내 이 
를 보상하기 위한 정상측 III V파 간 간격 연장에까지 이르게 된다(De Ridder et al., 2004). 본 증례의 청성뇌간반응검사에서 는 병변 부위인 우측의 파간 간격의 연장은 관찰되지 않았으나 파형의 전반적인 진폭의 감소가 동반되어 있었다. 이 결과는 와 우신경의 압박 초기의 신호전달장애는 있으나 탈수초화와 같은 신경의 진행성 병변은 없다는 사실을 시사한다.

Sunwoo et al.(2017)이 보고한 22예의 타자기 이명 환자의 경 우 증상이 발생하여 carbamazepine이 투여되기까지 6개월 7 년(평균 14.6 개월)의 오랜 기간이 소요되었고 이 환자 중 완전 하게 약물로 치료된(complete remission) 경우는 3예(13.6\%)에 지나지 않았다(Sunwoo et al., 2017). 국내에 보고된 7예의 경우 에도 환자들의 이환 기간에 대한 정확한 정보는 없지만 약물의 평균 투여기간은 평균 6.1개월(1 13.5개월)로 비교적 장기간의 투여가 필요했다(Kim et al., 2014). Carbamazepine은 백혈구 감소증, 혈소판 감소증, 재생불량성빈혈 등과 같은 조혈계 부작 용의 발생이 있고, 간기능, 신기능, 위장관계 이상 등의 부작용 의 우려가 있어 투여 전에 일반혈액검사 및 간기능, 신기능, 전 해질에 대한 초기 검사를 시행하고 초기 투여 2개월 동안은 2 주에 한 번씩, 이후 3 개월마다 일반 혈액검사 및 간기능검사를 시행하는 것이 권유되는 장기 투여에 대한 부담이 있는 약물이 기도 하다(American Psychiatric Association, 2002). 하지만 본 증례의 경우 증상 발현 15 일 만에 진단 및 투약이 이루어졌 고 단 3주간의 약물 투여로 이후 1 년 6 개월간 증상의 재발현이 없는 우수한 치료 결과를 보였다. 이는 본 증례에서 이전 연구 들과 다르게 약물의 진단적 조기 투여가 이루어졌고, 이로 인 해 혈관 압박에 의한 신경의 진행성 손상이 이른 시간에 차단 되어 와우신경의 불가역적인 변화가 방지되었고 더불어 빠른 신경 기능 회복이 이루어진 결과로 추정된다. 이를 토대로 타자 기 이명에 대한 조기 진단적 carbamazepine 투여가 짧은 투약 기간과 우수한 치료 효과를 보일 뿐 아니라 장기간 약물 복용 에 따른 부작용인 간 손상이나 조혈기능 억제 등의 부작용의 발현 빈도를 줄이는 동시에 질환의 재발을 방지하여 신속한 일 상 생활의 복귀를 가져온다고 추론해 볼 수 있다.

영상학적 검사의 필요성에 관하여 이견은 있으나 몇몇 연구 자들은 질환의 진단을 위해 이러한 검사가 필수적인 것은 아니 라고 주장한다. 15 명의 타자기 이명의 환자를 증상이 있는 환 측, 증상이 없는 건측, 질환이 없는 대조군의 일측으로 나누어 분석한 MRI 연구에서 세 군 간의 유의한 해부학적 이상(혈관 주행이 내이도를 압박하는 양상)의 차이는 없었으며(Bae et al., 2017), 이후 진행된 22명을 대상으로 시행한 MRI 분석에서도 신경과 혈관 간의 접촉이 없는 타자기 이명 환자가 가장 많은 비율(62.5\%)을 차지하였다(Sunwoo et al., 2017). 이러한 주장 을 토대로 본 증례에서는 환자의 전형적인 이명 양상(콩 볶는
듯한 소리)에 근거하여 MRI 촬영 이전에 carbamazepine을 투 여하였으며 환자는 투약 다음 날부터 완전히 이명이 소실되는 경과를 보였고, 이후 획득한 MRI 소견에서도 혈관과 신경 간의 접촉은 있었으나 내이도 내로 혈관고리의 침범은 관찰되지 않 아 전형적인 신경혈관 압박은 영상학적으로 증명되지 않았다.

수술에 의한 미세혈관 감압술(microvascular decompression)도 타자기 이명 치료의 한 방법이 될 수 있으나, 술자에 따 라 그 효과에 대해서는 다양한 성공률을 보고하고 있으며 (Guevara et al., 2008; Okamura et al., 2000; Ryu et al., 1999), $30 \%$ 이상의 환자에서 치료에 대한 반응이 없다는 연구 결과도 있다(Ryu et al., 1998). 또한 미세혈관 감압술 시 합병증으로 발생할 수 있는 완전 청력소실의 가능성을 고려할 때 carbamazepine 같은 우수한 진단적 치료 효과를 보이는 약물의 사용 이 수술보다 우선적으로 고려되어야 하며, 본 증례에서도 수술 적인 치료에 대한 일차적 고려 없이 약물의 투여가 선행되었다.

향후 치료 시점과 예후의 상관관계를 명확히 평가하기 위해 carbamazepine 투약 시기에 따른 타자기 이명의 예후를 평가 하는 임상연구가 필요하리라 생각된다. 본 저자들은 이명 발생 15일 만에 carbamazepine을 3주간 투여하여 완전히 이명이 사라진 증례를 경험하였다. 이에 영상학적 진단검사에 의존하 기 보다는 전형적인 이명의 양상에 의거하여 타자기 이명을 진 단하고 조기에 약물을 투여하는 것이 환자의 예후 향상에 도 움이 되리라 생각되며, 이 점을 명확히 하기 위해 향후 추가적 인 연구가 필요하다.

중심 단어 : 이명·카바마제핀·신경압박.

\section{Ethical Statement}

The entire procedure is approved by the Institutional Review Board of the Kangwon National University Hospital (IRB \# KNUH-2018-06-003).

\section{Acknowledgments}

The authors thanks to the participant.

\section{Declaration of Conflicting Interests}

There are no conflict interests.

Funding

N/A

\section{REFERENCES}

American Psychiatric Association. (1994). Practice guideline for the treatment of patients with bipolar disorder. American Journal of Psychiatry, 151(12 Suppl), 1-36.

American Psychiatric Association. (2002). Practice guideline for the treatment of patients with bipolar disorder (revision). American Journal of Psychiatry, 159(4 Suppl), 1-50.

Bae, Y. J., Jeon, Y. J., Choi, B. S., Koo, J. W., \& Song, J. J. (2017). The role of MRI in diagnosing neurovascular compression of the cochlear nerve resulting in typewriter tinnitus. American Journal of Neuroradiology, 38(6), 
1212-1217.

Baguley, D., McFerran, D., \& Hall, D. (2013). Tinnitus. Lancet, 382(9904), 1600-1607.

Brantberg, K. (2010). Paroxysmal staccato tinnitus: A carbamazepine responsive hyperactivity dysfunction symptom of the eighth cranial nerve. Journal of Neurology, Neurosurgery, and Psychiatry, 81(4), 451-455.

De Ridder, D., Ryu, H., Møller, A. R., Nowé, V., Van de Heyning, P., \& Verlooy, J. (2004). Functional anatomy of the human cochlear nerve and its role in microvascular decompressions for tinnitus. Neurosurgery, 54(2), 381-388; discussion 388-390.

Guevara, N., Deveze, A., Buza, V., Laffont, B., \& Magnan, J. (2008). Microvascular decompression of cochlear nerve for tinnitus incapacity: Presurgical data, surgical analyses and long-term follow-up of 15 patients. European Archives of Oto-Rhino-Laryngology, 265(4), 397-401.

Kim, D. H., Kim, H. J., Hong, S. K., \& Lee, H. J. (2014). Neurovascular compression syndrome of the eighth cranial nerve: Clinical features and medical treatment. Korean Journal of Otorhinolaryngology-Head and Neck Surgery, 57(8), 518-525.

Levine, R. A. (2006). Typewriter tinnitus: A carbamazepine-responsive syndrome related to auditory nerve vascular compression. ORL; Journal for Oto-rhino-laryngology and its Related Specialties, 68(1), 43-46; discussion 46-47.

Mardini, M. K. (1987). Ear-clicking "tinnitus" responding to carbamazepine. The New England Journal of Medicine, 317(24), 1542
Mathiesen, T. \& Brantberg, K. (2015). Microvascular decompression for typewriter tinnitus-case report. Acta Neurochirurgica, 157(2), 333-336.

Nam, E. C., Handzel, O., \& Levine, R. A. (2010). Carbamazepine responsive typewriter tinnitus from basilar invagination. Journal of Neurology, Neurosurgery, and Psychiatry, 81(4), 456-458.

Nondahl, D. M., Cruickshanks, K. J., Dalton, D. S., Klein, B. E., Klein, R., Schubert, C. R., et al. (2007). The impact of tinnitus on quality of life in older adults. Journal of the American Academy of Audiology, 18(3), 257-266.

Okamura, T., Kurokawa, Y., Ikeda, N., Abiko, S., Ideguchi, M., Watanabe, K., et al. (2000). Microvascular decompression for cochlear symptoms. Journal of Neurosurgery, 93(3), 421-426.

Ryu, H., Yamamoto, S., Sugiyama, K., Nishizawa, S., \& Nozue, M. (1999). Neurovascular compression syndrome of the eighth cranial nerve. Can the site of compression explain the symptoms? Acta Neurochirurgica, 141(5), 495-501.

Ryu, H., Yamamoto, S., Sugiyama, K., \& Nozue, M. (1998). Neurovascular compression syndrome of the eighth cranial nerve. What are the most reliable diagnostic signs? Acta Neurochirurgica, 140(12), 1279-1286.

Sunwoo, W., Jeon, Y. J., Bae, Y. J., Jang, J. H., Koo, J. W., \& Song, J. J. (2017). Typewriter tinnitus revisited: The typical symptoms and the initial response to carbamazepine are the most reliable diagnostic clues. Scientific Reports, 7(1), 10615. 